\title{
Flipped Classroom Based on Internet plus Education and Smart Learning
}

\author{
Feifan Shen*, Lingjian Ye, Xiushui Ma, Weihong Zhong \\ Ningbo Institute of Technology, Zhejiang University \\ Ningbo 315100, Zhejiang, China \\ anhalt@zju.edu.cn, ljye@nit.net.cn, mxsh63@aliyun.com, zwh@nit.net.cn
}

\begin{abstract}
The effectiveness of the flipped classroom in college education is largely improved by combined with smart learning strategies recent years. However, most traditional smart learning methods focus on the use of smart devices in the learning step and ignore the in-classroom application. Meanwhile, with the appearance of "Internet plus education", more and more online education platforms are available for mobile devices. To meet the increasing demand of the flipped classroom based on the online education; this study aims at extending the are a of smart le arning into the in-class study. A novel smart learning based education paradigm is proposed by re-designing the structure of the traditional flipped classroom. In the new teaching structure, the performance of the flipped classroom can be improved obviously since smart learning strategies become the key element which spreads through all the procedure. For performance evaluation, a preliminary practice of a college course has been conducted and the result shows the advantage of the proposed paradigm.
\end{abstract}

Keywords-smart learning; internet plus education; flipped classroom; college education

\section{INTRODUCTION}

During recent years, the rapid development of smart device technology leads to lower cost and better performance of related products such as smartphones and smart pads. Meanwhile, the owning rate of smart devices among college students is able to meet the demand of smart learning. On the other hand, the concept of "Internet plus" has brought about a large number of internet-related applications in many areas. Combined with such ideas, "Internet plus education" is becoming a hot strategy for innovative reforms of the teaching field. By the use of both smart devices and internet resources, teaching out of classroom is no longer a difficult task for the flipped classroom. On the contrary, it is quite convenient for students to take full advantage of the flipped classroom strategy with an easy access to different teaching materials.

Focusing on the application of smart devices in the flipped classroom, scholars proposed many detailed strategies to improve the performance of such applications. Kim analyzed the effectiveness of the flipped classroom by using smart pads instead of traditional ways and proved the improvement of collaborative learning and information using ability of smart learning as a result [1]. Garcia made an experiment by introducing information and information technology (ICT) into the flipped classroom, in particular smartphones, to evaluate the performance of the implement of ICT and finally conclude

This work was supported by Ningbo Education Planning Project (2016YGH032) that the combination of the flipped classroom and ICT has positive effects on education [2]. Lately, Peng reformed the college English teaching mode by providing micro class in mobile environment and improved the effectiveness of the flipped classroom [3]. Then, Qi proved that mobile learning has great advantages along with the flipped classroom compared with traditional teaching modes [4]. WindmullerCampione developed an active learning method by using smartphones in the flipped classroom in the silviculture teaching case [5].

Although many existing methods have developed the teaching mode by using smart devices in the flipped classroom, most of them just regarded smart devices as video terminals to deliver knowledge out of classroom. Under such a situation, smart devices function little during the test and level-up study procedures, which are two critical steps during a flipped classroom. However, with the rapid development of internet, other significant functions of smart devices should not be ignored nowadays. Smart learning, combined with "Internet plus education" mode, will develop more possibilities of the flipped classroom for college students. In this paper, the use of smart devices will expand from the learning procedure into the classroom by introducing internet resources to the test and level-up study procedures. The proposed strategy aims at improve the effectiveness of smart learning base on the flipped classroom by making full use of internet and corresponding applications.

The rest of this paper is organized as follows: Section II describes some preliminaries related to the flipped classroom and the detailed model and description of the proposed method. Section III provides a preliminary practice to prove the effectiveness of the proposed method. Finally, conclusion is made in Section IV.

\section{APPLICATION OF INTERNET AND SMART LEARNING IN FLIPPED CLASSROOM}

\section{A. The flipped classroom}

The flipped classroom has existed for more than ten years after the appearance of the similar education mode. Lage and his colleagues firstly illustrated the teaching and learning mode of the flipped classroom and the achievement they made on economic courses in University of Miami [6]. The name of "flipped classroom" was lately proposed by Baker in the 11th International Conference on College Teaching and Learning 
[7]. Then, numerous strategies of the flipped classroom were proposed such as recording lessons and providing to publics out of classroom.

The crucial innovation of the flipped classroom is totally changing the way of studying for student. The main idea to implement it is involved with two parts: one is extracting the learning step out of classroom through online videos and other approaches; the other one is taking the traditional after-class tasks into the classroom. In the traditional teaching mode, "teach, practice and review" are three key elements and due to this structure, teachers are the major characters in college education. Oppositely, the flipped classroom takes students to the center of the stage by designing a "learn, test and level-up study" structure. The most important improvement is extracting the learning procedure out of classroom by students themselves and sparing more in-class time for teachers to guide students to find their weakness on relevant knowledge. In-class tests and discussions are carried out to obtain feedback from students immediately.

\section{B. Smart learning in the flipped classroom}

In the beginning, the learning step of the flipped classroom was usually involved with video watching in television. As a result, the materials for study were limited and teachers might take more time to illustrate the relevant knowledge for students in classroom. Thus, the effectiveness of in-class tests and study was affected since the planning time was occupied. Fortunately, the development of smart devices such as smartphones and smart pads provides the flipped classroom with various preclass learning approaches expect for videos. Besides, other smart learning strategies are proposed during in-class study such as reviewing video lessons. The detailed structure of a flipped classroom based on smart learning can be described in Fig.1 [8].

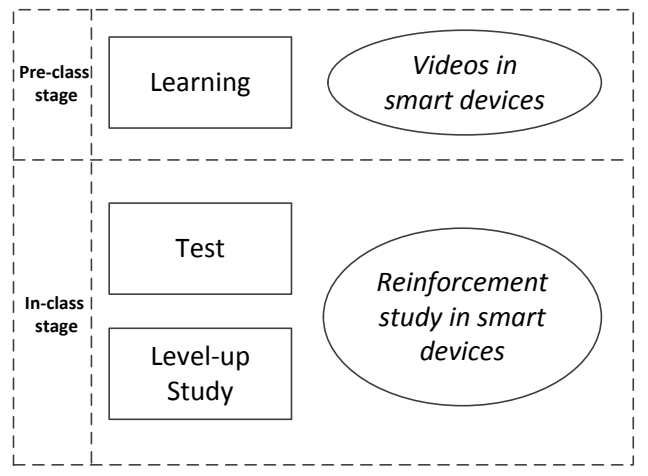

Fig. 1. Structure of the traditional smart learning model of flipped classroom

\section{Motivations}

Although the flipped classroom based on smart learning has been proved effective in college education, the potentials of smart devices have not been fully explored combined with the internet. The major problems of the current smart learning strategies are described as follows:

- Pre-class learning materials are still limited. The occurrence of advanced smart devices offers students convenient video players instead of learning in front of televisions with video tapes. However, smart devices today are able to achieve more complicated tasks with the help of internet. As a result, it is necessary to combine the advanced smart devices and internet applications to provide college students with a various choices of pre-class learning.

- Most smart devices used in class are bounded to individuals and few interactions between teachers and students are happened with these devices. In fact, communications are much easier these days owing to the internet. Making use of both smart devices and the internet in the flipped classroom is becoming a critical issue to improve the effectiveness of smart learning.

- In-class smart learning is faced with a serious problem for college students that it may cause distraction while using smart devices. Various applications for entertainment on smart devices are available with the internet. College students should resist the temptation of irrelevant applications while using smart devices in the classroom.

\section{The flipped classroom with internet plus smart learning}

Taking these motivations into consideration, we propose an improved flipped classroom model in order to resolve existing problems. Compared to the traditional flipped classroom based on smart learning, we preserve the advantages of the old model and modify part of the details to generate an improved model. The new structure of the proposed strategy is shown in Fig.2.

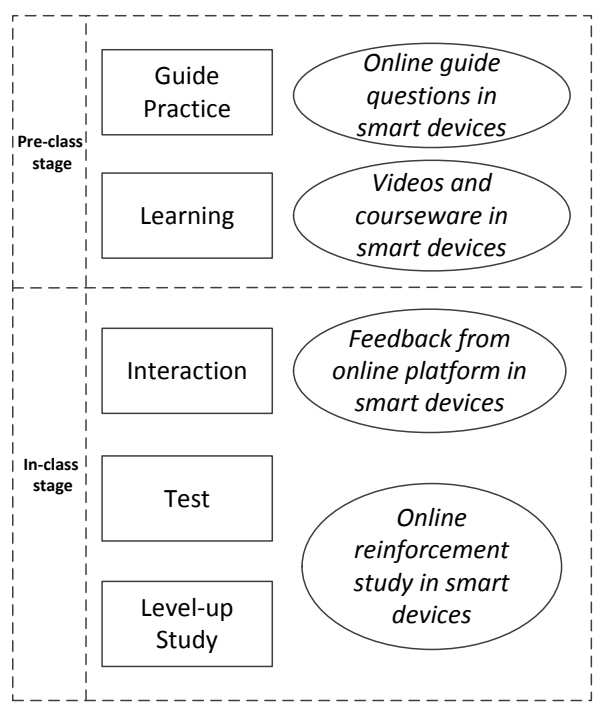

Fig. 2. Structure of the new smart learning model of flipped classroom

Different from the traditional smart learning model of the flipped classroom, the new structure focuses on the online applications which integrate both smart devices and the internet. Therefore, "Internet plus education" can play an important role in the flipped classroom.

During the pre-class stage, a guide practice is set in this model. Cases are introduced and relevant questions are provided to lead the students into the new chapter. The learning 
interest of students can be stimulated and students are able to learn the knowledge on the basis of guide questions. In the learning step, courseware is uploaded through online education platform of smart devices as well as videos, which offer students multiple choices to learn.

Then it comes to the in-class stage. Unlike the traditional model, an interaction step is added to obtain the feedback of the pre-class stage. Surveys are conducted through online education platform to collect the information of the accuracy of guide questions and the learning rate of videos and courseware. According to the results of the interaction step, tests and levelup study can be implemented with significant references, which can definitely promote the effectiveness of the in-class study. Besides, online reinforcement study tasks such as tests and quiz in smart devices is carried out to ensure the comprehension of the new knowledge for college students.

\section{E. Advantages of the proposed model}

The proposed model is a promoting strategy on the basis of the traditional smart learning based flipped classroom for college education. Motivated by the defections of the traditional model, online education platforms are introduced to make full use of smart devices to achieve "Internet plus education". The major advantages of the proposed model are listed as follows:

- Pre-class learning materials are various for college students to choose from. Smart devices, together with online education platforms, are able to bring about more learning approaches except for videos. Courseware and other materials are introduced into the pre-class learning stage that students can focus on their favorite learning materials.

- The guide questions and the interaction steps, which are the new parts in the proposed model, can provide college students with more chances to communicate with each other through online applications in smart devices. Proper communications can help students recognize whether they have understood the essential knowledge points.

- To resolve the distraction problem of college students while using smart devices in class, statistical tools are adopted to record the total time that students use education platforms. When the time is not enough for learning purpose, alarms will be sent to both teachers and students. It can promote the self-conscience when college students are using smart devices in class and avoid the distraction caused by irrelevant application.

\section{Preliminary Practice}

\section{A. Backgrounds}

In the preliminary practice section, the course named "Process Control \& Instrumentation Technology" (PCIT) is conducted to evaluate the effectiveness of the proposed model. This course aims at making college students have a basic understanding of process control and industrial instrument. Not only the students who major in automation have the chance to attend this course, other students whose majors are related to chemical processes can also participate in it. As a result, not all the students attending this course can understand the knowledge of process control and instrument easily since some of them may have little prior experience of the knowledge. In this course, there are 8 teaching units totally and 135 minutes for each unit.

\section{B. Design of one unit with the proposed model}

The chapter "flowmeter" is an important knowledge point of instrument technology. The customized design of the flipped classroom based on improved smart learning is presented in TABLE I.

\section{TABLE I. CUSTOMIZED STRATEGIES OF FLOWMETER IN PCIT}

\begin{tabular}{|c|c|}
\hline $\begin{array}{c}\text { Customized } \\
\text { Stage }\end{array}$ & Detailed Strategy \\
\hline $\begin{array}{c}\text { Guide } \\
\text { questions }\end{array}$ & $\begin{array}{c}\text { brainstorming about flowmeters used in daily life; } \\
\text { guessing purposes of flowmeters in given pictures }\end{array}$ \\
\hline Learning & $\begin{array}{c}\text { Watching videos of real-time flowmeters in process industry; } \\
\text { Studying on courseware with detailed knowledge points; }\end{array}$ \\
\hline Interaction & $\begin{array}{c}\text { Gathering the answers of guide questions in smart devices } \\
\text { Face-to-face communications according to the results }\end{array}$ \\
\hline
\end{tabular}

The guide questions step is an additional part compared with the traditional smart learning model. Firstly, a brainstorming is required through online education platforms in smart devices. The answers from students will be gathered and stored for further use. Then, several pictures of flowmeters used in process industry are provided for students to guess the detailed purpose. The correct answers will be shown after the guesses are done. The guide questions part is designed to inspire the interest of college students before learning.

The traditional learning step of the flowmeter chapter mainly relies on videos consisting of knowledge points. In this preliminary practice, videos of running flowmeter (e.g., turbine flowmeter, vortex flowmeter, ultrasonic flowmeter) in practical industry are presented, which are able to promote the interest of students about flowmeters. Meanwhile, knowledge points are summarized into courseware to offer a better view of the detailed descriptions of flowmeters.

In order to obtain the feedback of guide questions before further tests and level-up study, answers will be gathered and the teachers can continue the in-class teaching referring to the knowledge level of students. Furthermore, flowmeters are exhibit to students during the face-to-face communication step. Thus, students are able to have a direct observation of the flowmeter structures.

\section{Results}

The feedback of the preliminary practice is collected from students who major in pharmaceutical engineering. The detailed results of the promoted model according to the survey are shown in TABLE II. 
TABLE II. RESUlts OF THE PRELIMINARY PRACTICE

\begin{tabular}{|c|c|c|c|}
\hline \multirow{2}{*}{ Category } & \multicolumn{3}{|c|}{ Satisfaction of Study } \\
\cline { 2 - 4 } & Poor & Good & Excellent \\
\hline $\begin{array}{c}\text { Pre-class } \\
\text { Stage }\end{array}$ & $4.8 \%$ & $21.4 \%$ & $73.8 \%$ \\
\hline $\begin{array}{c}\text { In-class } \\
\text { Stage }\end{array}$ & $0.0 \%$ & $16.7 \%$ & $83.3 \%$ \\
\hline $\begin{array}{c}\text { Mastery of } \\
\text { Knowledge }\end{array}$ & $0.0 \%$ & $33.3 \%$ & $66.7 \%$ \\
\hline
\end{tabular}

It can be inferred that by the use of the improved model, the percentage of the students that feel satisfied with the course is significant. Both stages provide promoted leaning strategies and mostly lead to good/excellent learning results. After the class, most students feel the proposed learning mode novel and interesting and waste less time on irrelevant applications in smart-devices.

In general, the effectiveness of the proposed model is demonstrated by the after-class feedback from students. Meanwhile, the concentrations of students are obviously improved with the influence of more communications according to the feedback from teachers. It should be noticed that a few students are not so satisfied with the pre-class stage, which means that the learning step should be improved yet.

\section{CONCLUSIONS}

In this paper, a novel flipped classroom based on smart learning and "Internet plus education" is proposed to improve the performance of the flipped classroom in college education. Motivated by the disadvantages of the traditional flipped classroom based on smart learning, a customized model is developed combined with online applications in smart devices.
Guide questions and interaction steps are introduced and the learning step is modified. A preliminary practice of "PCIT" is carried out to testify the effectiveness of the proposed model. According to the feedback from the students and teachers, the results are positive and satisfying. In the future, our work will focus on the further improvement of the pre-class study performance.

\section{REFERENCES}

[1] H. K. Sang, N. H. Park and K. H. Joo, "Analysis of effectiveness of flipped classroom based on smart learning," Next Generation Computer and Information Technology, p. 107-111, 2014.

[2] I. G. Garcia, N. C. Lemus and P. T. Morales, "The flipped classroom through the smartphone: Effects of its experimentation in high school physical education," Prisma Social, 2015, vol. 15, pp. 296-352, 2015.

[3] B. Z. Peng, "College english flipped classroom teaching mode based on micro class in the mobile environment," Journal of Heilongjiang College of Education, 2016, vol. 5, pp. 127-129, 2016.

[4] X. Qi and Y. Zhang, "Application of mobile learning based on smart phone in the flipped classroom," Wireless Internet Technology, 2016, vol. 2, pp. 99-100, 2016.

[5] M. A. Windmuller-Campione and D. R. Carter, "Active learning using smart phones in a flipped classroom: A case study on developing final videos in silviculture," Journal of Natural Resources \& Life Sciences Education, 2017, vol. 46, pp. 1-9, 2017.

[6] M. J. Lage, G. J. Platt and M. Treglia, "Inverting the classroom: A gateway to creating an inclusive learning environment," Journal of Economic Education, 2000, vol. 31, pp. 30-43, 2000.

[7] J. W. Baker, "The "classroom flip": Using web course management tools to become the guide on the side," The 11th International Conference on College Teaching and Learning, p. 10-22., 2000.

[8] L. Ye, X. Ma, W. Zhong and H. Guan, "Teaching paradigm reform based on semi-flipped classroom and a preliminary practice," International Seminar on Education Innovation and Economic Management, p. 1-4, 2017. 